\title{
المسيح المخلص و فكرة الخلاص - في الفلسفة الهيغيلية -
}

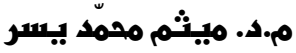

كلية الآداب - جامعة واستط

\section{التمشميد- فكرة المغلص أو (الماسيا):}

إنَّ فكرة المسيح المخلص (المنقذ مؤدّاهاً : أنَّ المسيح (عليه السـلام) يعود في آخر الزمان مرة أخرى ، لإنقاذ

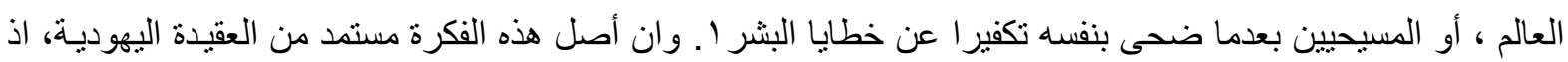

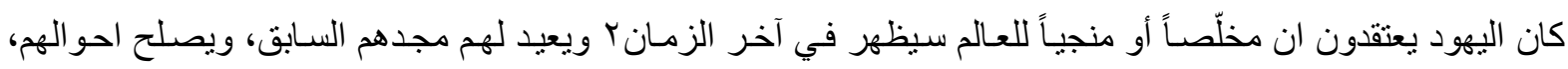
وينصفهم من الظلم الذي وقع عليهم عبر التاريخ ، بخاصة بعد خر اب دولتهم وتشتتهم في الاصقاع وتعرضهم الى القتل و السبي و التشريد والاستعباد على مرّ الزمان. ولو عدنا الى اصل الكلمة نجد انها مستله من كلمة (مانشيح) : و هي كلمـة عبريّة تعني (المسيح المخلص) ومنها (مشيحوت) أي: (المشيحانية)، وهي ايضـاً الاعتقاد بمجيء

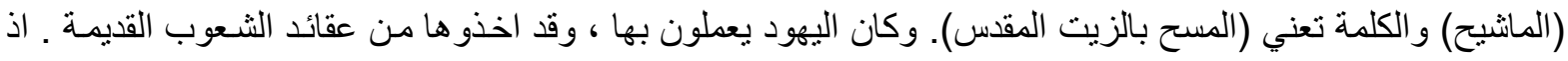
يمسحون راس الملك او الكاهن بالزيت قبل تتصيبه وهي علامة على المكانه الخاصة الجديدة ، و وعلامة أنَّ الروح الإلهية

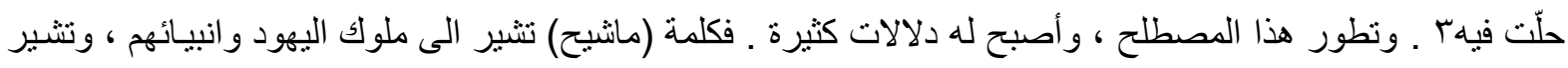

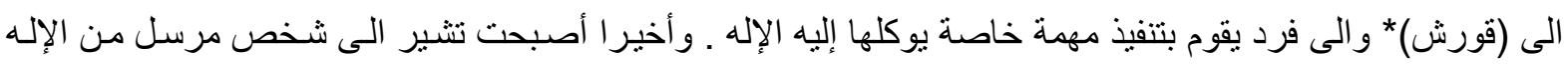

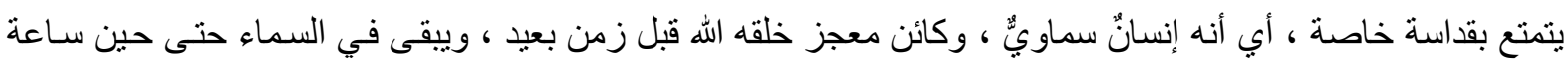

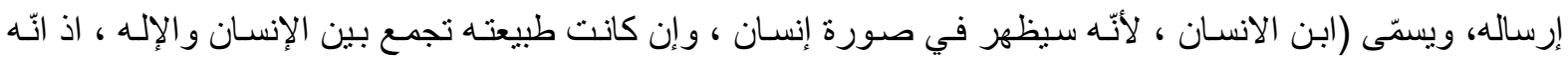

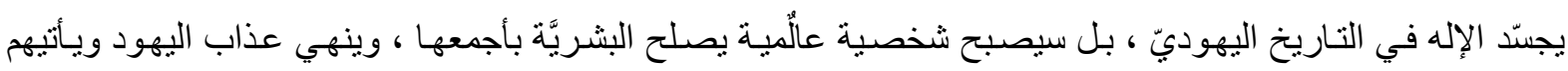

\section{فكرة المسيج المفلص عند المسيميسن:-}

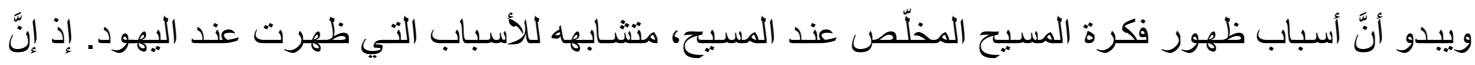

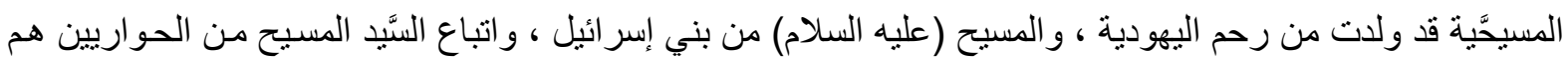

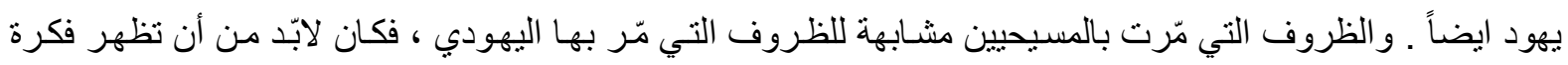
المخلّص الذي سيظهر ويحكم بالعدل ويقضي على الظلم و الفساد. فالمسيحيون بعد عيسى بن مريم قد عاشتوا الظلم

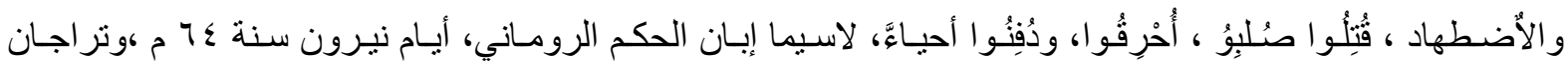

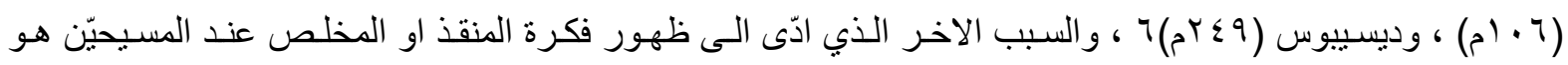

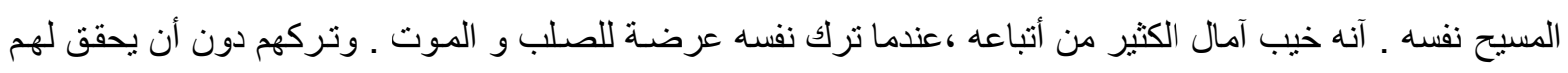

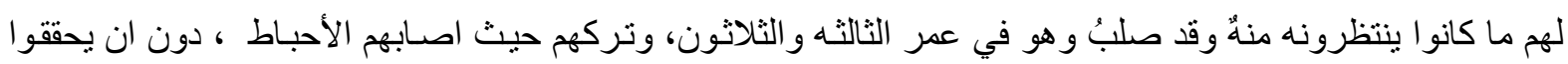

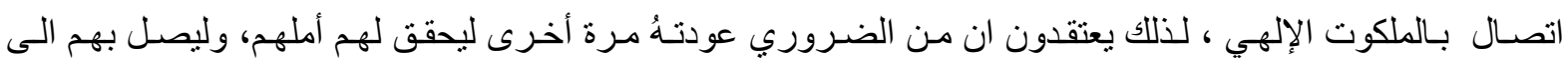
الملكوتV. لذى نجد ان الاناجيل حافلة بالتبشير بمجيء المخلّص (ماسبّا). ففي أنجيل [يوحنـا ، لوقا، متي ......] نجد بعض النصوص نثير الى ذلك مثل ((هو ذا يأتي مع السحاب ، وستنتظره كل عين، والذين طعنوه وستنوح عليه، 
جميع قبائل الارض)(^ وفي اعمـال الرسل نجدهم يبشرون بموت المسيح وقيامتهـ وصسوده الى السماء مؤكدين أنّ الماسيّا الذي تمت فيه النبو عات الذي أنت به عمل الفداء كما يقول بطرس الرسول سيظهر من جديد.

وتؤكد نصوص أخرى الايمان بفكرة العودة تللك، وجدناه في انجيل يوحنا اذ يقول: ((الحقّ الحقّ أقولُ لكم ، إنّهـ

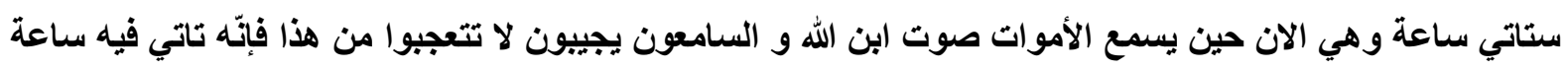

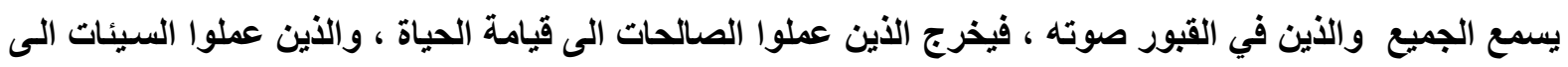
ق فيامة الدينونة)) وفي حديث السيد المسيح على جبل الزيتون الى حوارييه يكثف عن ظهوره مرة ثانية ويوضح علامـات الظهور

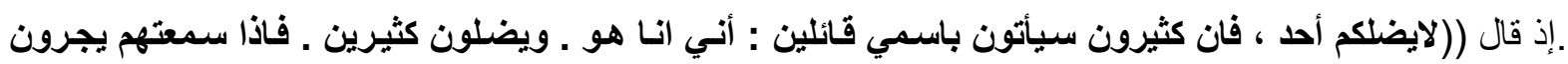

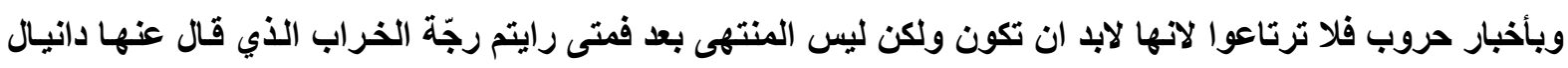

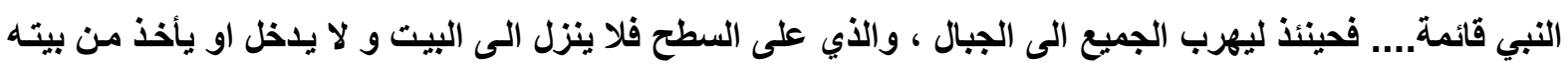

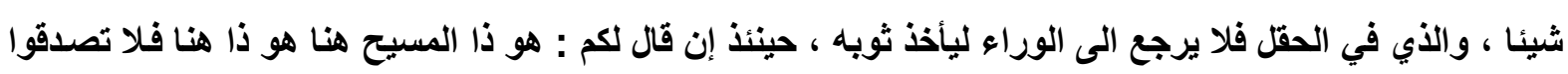

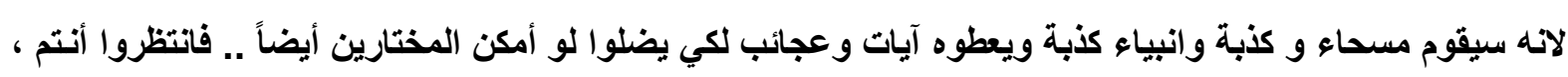

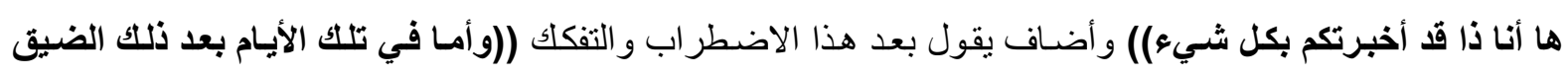
والشمس تظلم ، والقمر لا يعطي ضوء ونجوم السماء تتسـاقط ، والقوات التي في السماء تتزعزع ، يبصرون ابن

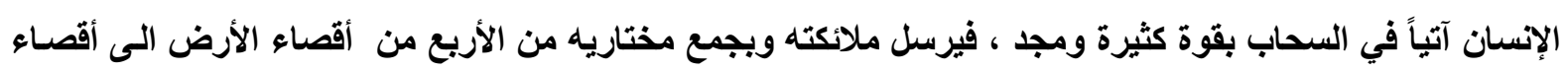

الأرض)(الإسنان

إن تللك النصوص التي اوردناه نؤكد عوده المسيح المخلّص (ماسيّا). و هي دلالة على تغلغل تللك الفكرة في

الديانة المسيحة حيث أصبحت عقيدة راسخة عند معظم المسيحين من لاهو تييهم وفلاسفتهر.

أن فكرة المنقذ أو المصلح او المخلص تكثف ، بطبيعة الحال ، عن و اقع الإنسان وفكره وآماله. في تحقيق العدالة

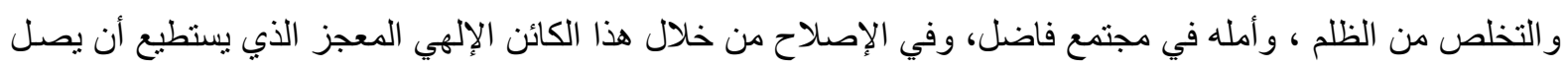
بالإنسان إلى اعلى مستوى من الوعي و الإيمان و المعرفة. وفئ. وفئ.

إن كلّ النصوص تثير الى أنّ المخلّص يأتي لينقذ البشرية جمعاء من و اقع اجتماعيّ و اقتصاديّ وسياسيّ متردّي

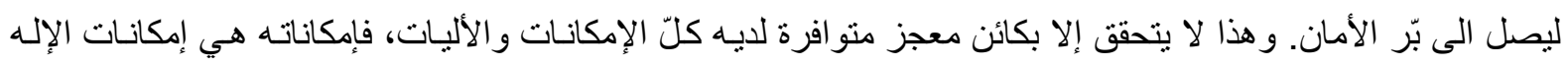

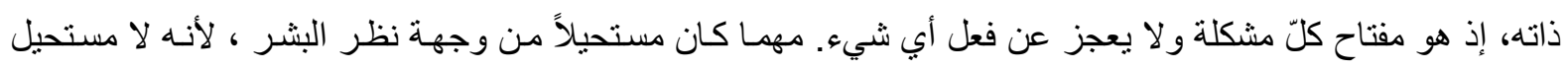

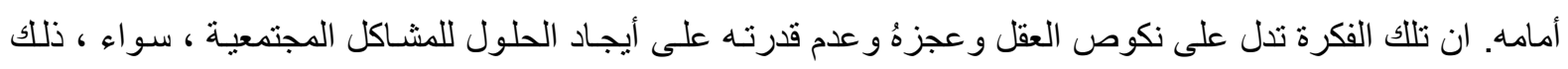
على مستوى الفكر والاقتصاد او السياسية او جو انب الحياة الاجتماعية الأخرى ، و وهي دليل على فئل فيل العقل الإنساني

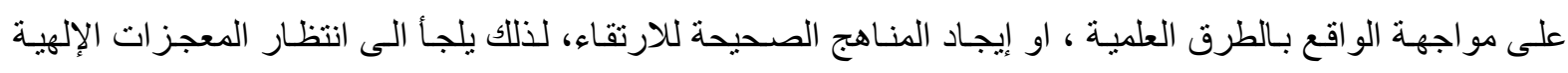
ليوظفها لحل مشاكله اليومية ،ويأمل في حياة أخرى سعيدة.

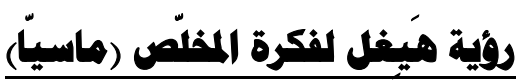

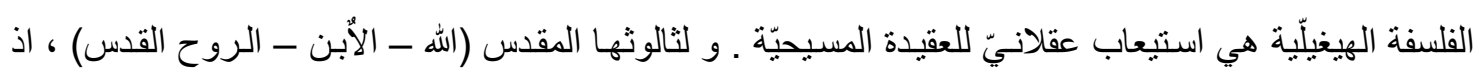
يقابلها في المذهب الهيغيليّ الفكر الكلي (الله ـ فكرة خالص) ، و الفكر الجزئي (الله ـ الأبن وقد تغلغل في الطبيعـة ) 
الفكر الفردي (الروح القس). الله وقد أكتسب معرفة جديدة وتخلص من المادة ـ أذ إنّ الروح القدس تجمع النقيضين في

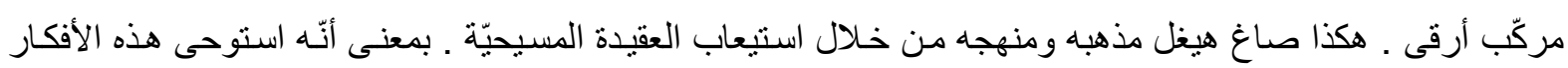
ووظفها ضمن مشرو عه الفلسفي الثنامل.

إنَّ مشروع هيغل الذي طرحهه في كتاب (الفينومينولوجيا) يكثف فيه عن حركة الفكر منذ بدايـة الوعي بكل توجهاته وتشعباته وتطوره الى زمن الفيلسوف. فهو رصد لنشاط العقل الإنساني منذ البداية الى ان اصبح فكر أ تصورياً

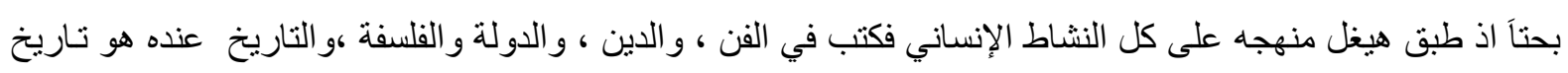
تطور العقل و اللحظات الحاسمة فيه هي لحظات انتقال العقل الإنساني من مستوى و عي مندن الى مستوى اعلى و أرقئ .

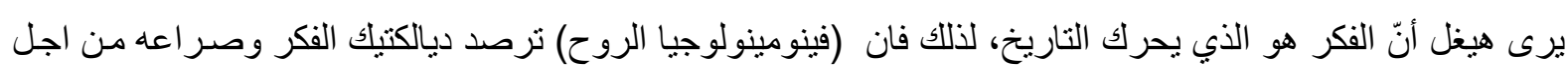

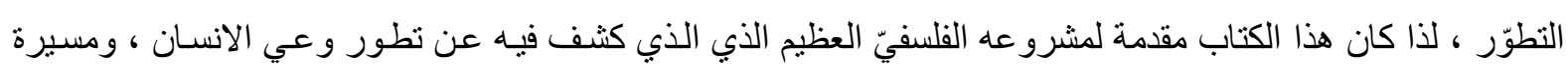

الروح نحو المطلق (الله).

\section{هنهوم الروح المطلق عند هيغل:-}

استعار هيغل المفاهيم الذي تفترض إلهاً متعالياً ، وذاتاً مستقلاّ وكان يرى أنّ المتناهي (الإنسان) هو فترة أساسيّة

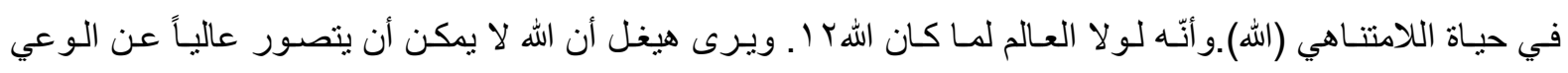

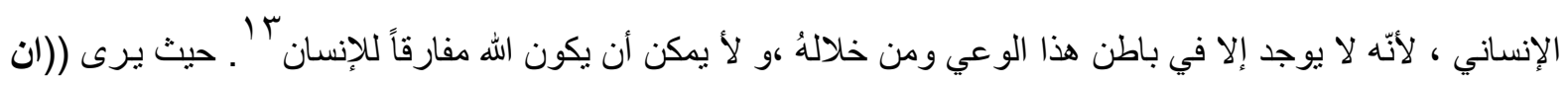

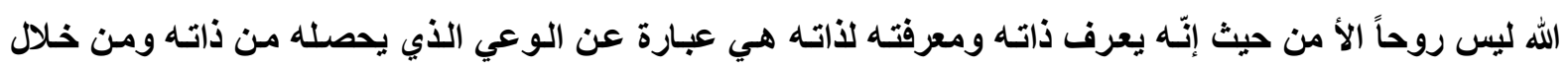

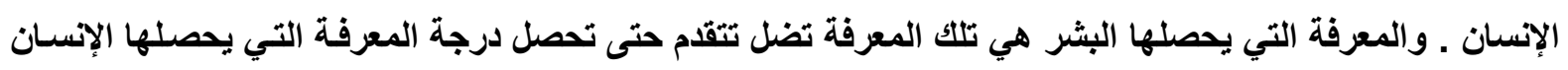
عن ذاته)) 'ا ـ وفي تصوره للروح المطلق يرى ((إنّ الماهية الكلية للروح تتخصص في أرواح فرديـة تعي الماهية الكلية وتعي تطابقها الذاتي معها وهذه هي الصورة التي تعرف بها هذه الماهية نفسها وتصبح روحاً حقاً) 10 ــ وعندما

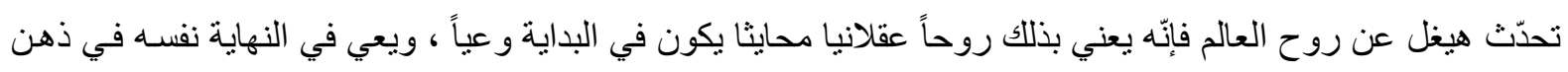
الفيلسوف. إن الفكرة المطلقة كمـا يقول [رينة سرو] ليس سوى الانموذج المثنالي للروح المحروم ليس فقط من وعي خاص بل من الوجود الخاص وإنه يتحقق فقط في الأرواحV ا. إن المطلق الذي أثنار اليه هيغل في الفينومينولوجيا على أنه منظومـة (systeme) هو في جوهره وحدة الروح التي تبث نواز عها ديالكتيكيا في عروق المتعدد ، أيّ في عالم المشاركة ، ويتعلّق أمر العالم بالمشـاركة ليس في انسياق

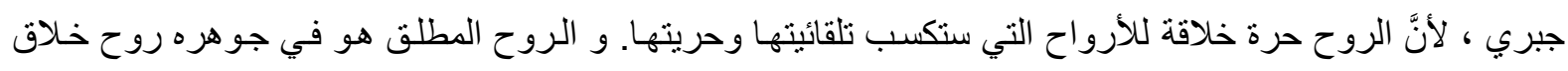

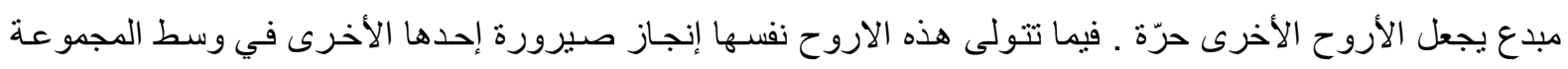
البشرية.

إنّ مسيرة الروح تتكامل من خلال الحركة نحو هدفها أو غايتها ، عبر التاريخ ـ وكل مسيرة العالم سـائرة نحو

هدف أوغاية محددة هي (تصالح النهائي مع اللانهائي). وبعبارة أخرى (اندماج ما هو معطى في نهائية لفكرة). إنّ مسيره الروح المطلق صوب التحقق تمثلّ كلّ نشـاطات الحياة ـ إنّها نقد للوعيّ وللفكر عبر الزمن أي من خلال وعي الأنسان وتقدم فكره عبر الزمن ، فالمطلق يتجلّى من خلال هذه المسيرة عبر ديالكتيك صـاعد ولكن ليس 
باتجاه واحد. و إنَّ أصعب ما يو اجهه دارسو الفكر الهيغيلي يكمن في تبيان طبيعة الروح المطلق. و إنّ الإشكال والصور

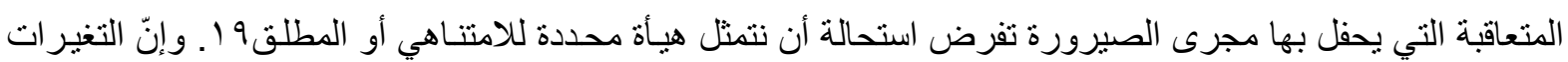
التي تصيب الأشياء تمر عبر الزمن ، وتقوم اساساً على ضرورة احلالها وانتمائها في المطلق (الله).

المسيحية وفكرة تحقيق المطلق: لقد شخص هيغل حركة الروح (الفكر) ،من خلال نشاط البشرية عبر التاريخ ، ور آى إنّ تطور الفكر يمر عبر

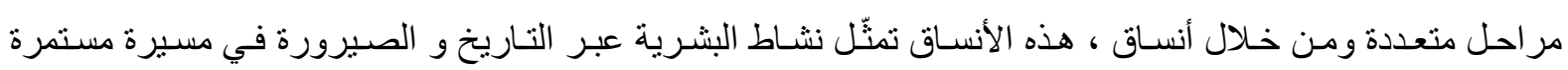

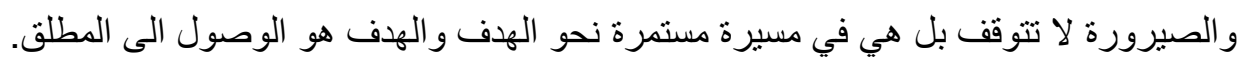

إنّ الدين هو مرحلة من مر احل تطوّر الروح وترقيها وكثف نشاط الروح وتجلّيّها ـ ويعدُ الدين عند هيغل مرحلة

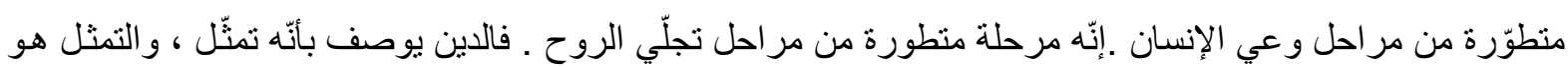

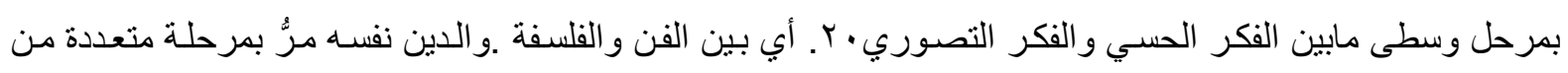

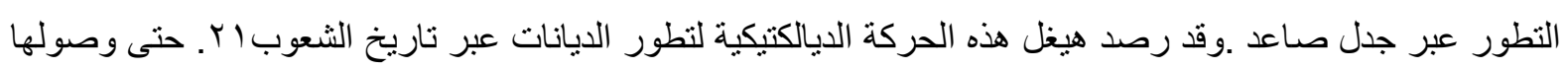

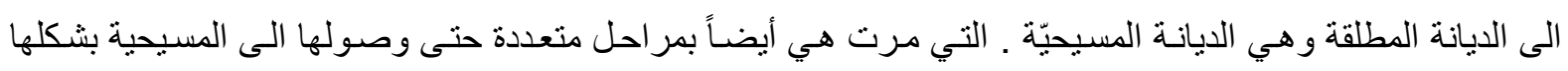
(البروتستانتي) .و هي الديانة المطلقة بحسب هيغل ـ و البروتستانتية التي اعتبر ها أساس الفلسفة الحديثة هي التي أصبحت التبن

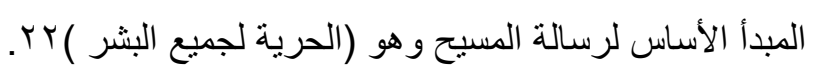
لقد رصد هيغل تطور المسيحية من خلال مسيرة السيد المسيح عليه السلام الى أن نضجت هذه الديانـة على يد

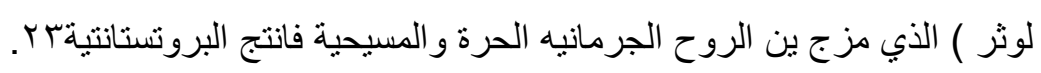
يعد هيغل ظهور المسيح الابن في الطبيعة (هناو الأن) خطوة متقدمة في مسيرة المطلق. إذ لأول مرة في التاريخ

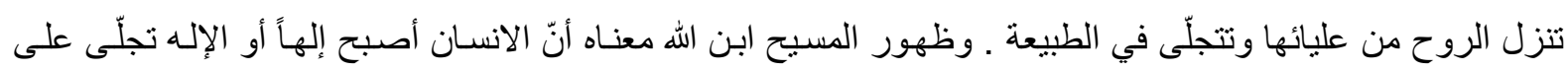

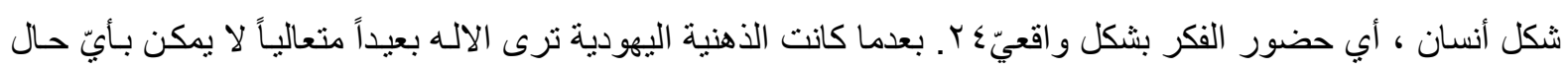

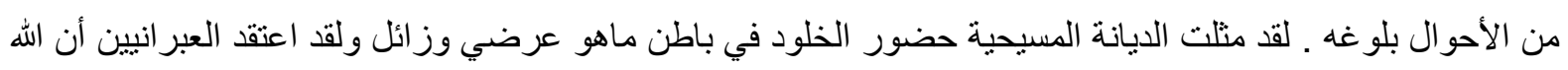

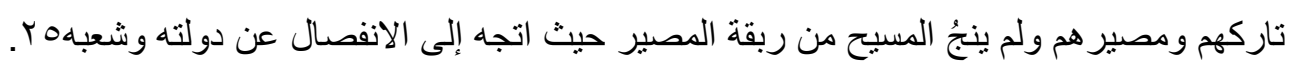
لقد عرف تلاميذ السيد المسيح وحواريوه السيد المسيح عن قرب ورأوه واستمعوا اليه ولكن هذا المسيح التاريخي

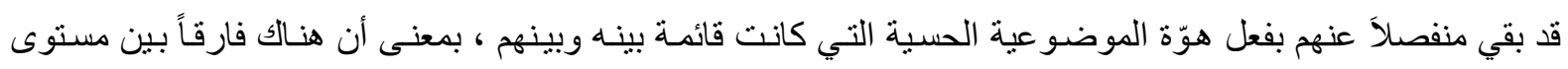

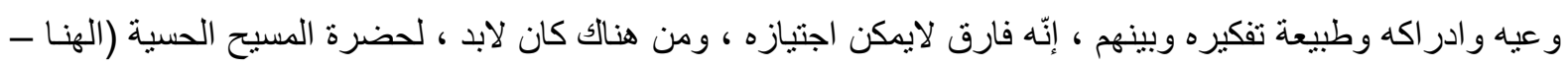

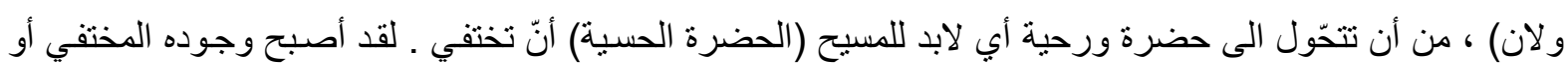

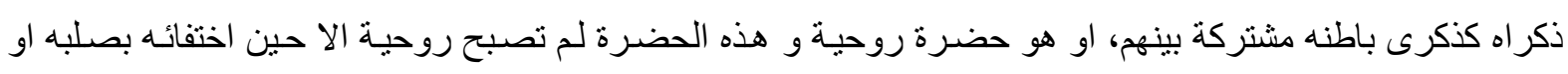

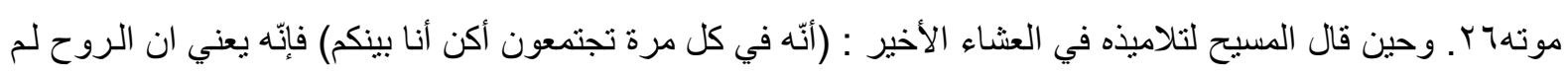

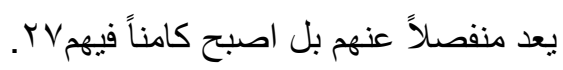

إن موت المسيح قد اندمج في روح الجماعة فأصبح كتعبير عن الوعي الذاتي الكُلِّيّ لهم ـ أب أن الفعل الذي تحقق

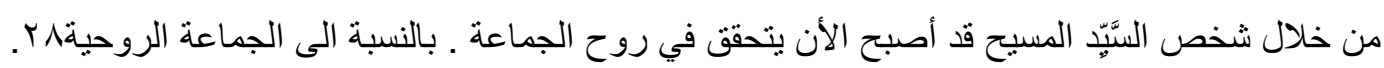


إن الحاضر المبانـر (الأن) أصبح ماضياً ، وقد انقضى ، وعلى هذا فإن الفكرة الحّسيّة قبل كل شـي تجعل

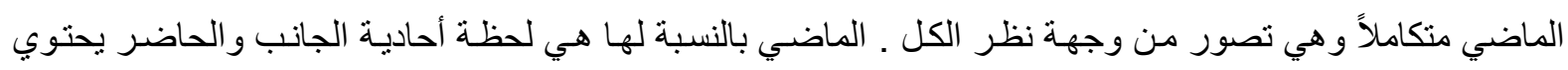

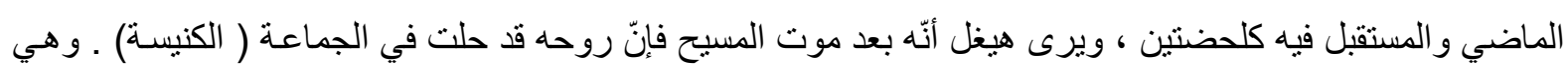

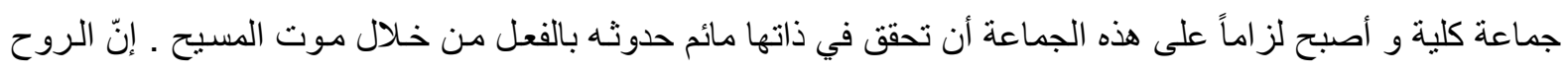

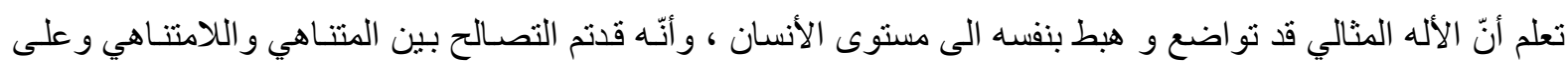

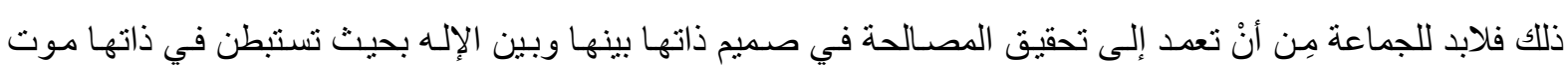

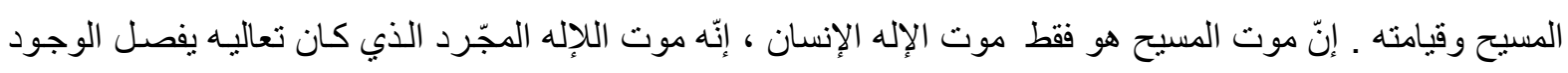
البشري فصلاً جذرياً عن ماهيته.

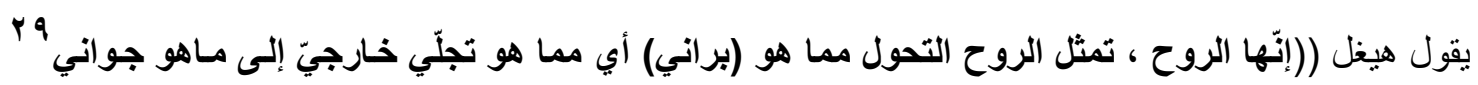
وهذا التحول يشغل باليقين الذي تستحضره الذات بجوهريتها اللامتناهية ـ وحقيقة أنها تعرف ذاتها على أنها لامتناهية التهية

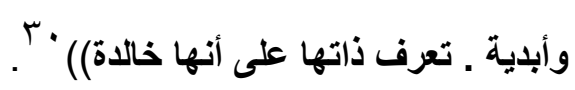
ويوضح هيغل هذا التطور الفكري المفصليّ في الديانة المسيحية فيقول (وهذا التحول هو تدفق الروح و الذي يمكن أن لايحصل ظهوره الا بعد أن انتزع المسيح من الجسم وتوقف الحاضر المباثـر الحسي وحينئ تظهر الروح حاضرة بالنسبة للادراك الحسي (الأن) هو شي مختلف وله شكل)) ' ل.

إنّ التحليلات الهيغيلية لقصة المسيح و لادته حضوره ـ موتهـ ـ قيامته) يعطي بعداً ، معرفياً و عقلانياً . إنّهـ لا

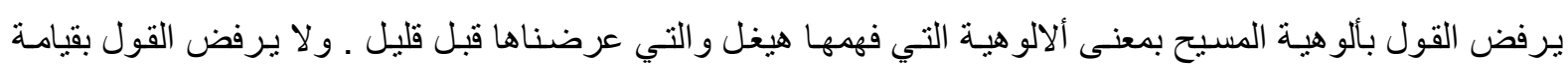

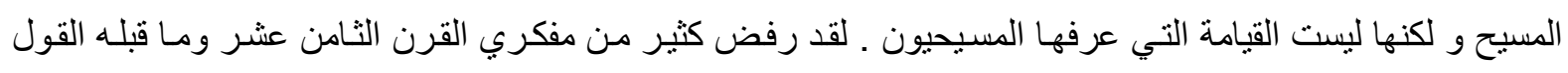

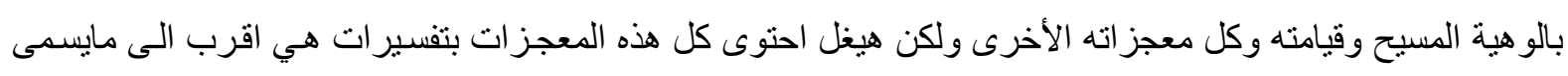

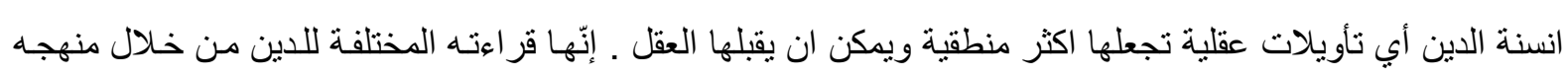
الذي استو عب الوعي الإنساني كله الذي حاول ان يستو عب الوجود كله .

ان المسيح كظاهرة فكرية كان حتمياً في مسيرة الروح ـ بمعنى أنّ الواقع الفكري ومستوى الوعي الذي انتجهـ

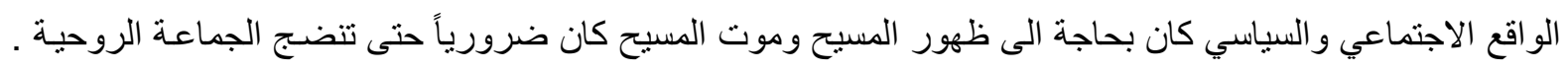

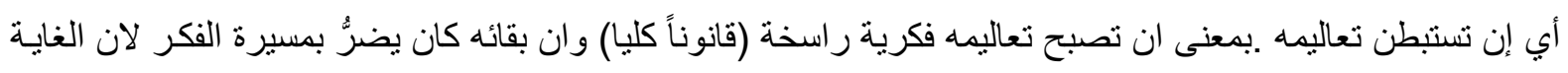

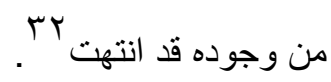

إنّ حضور المسيح داخل الجماعـة الروحيـة ، بشكله الروحي الحسي المعبر عن الوهية الانسـان اصبح مضراً

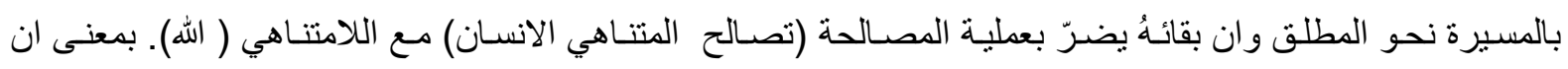

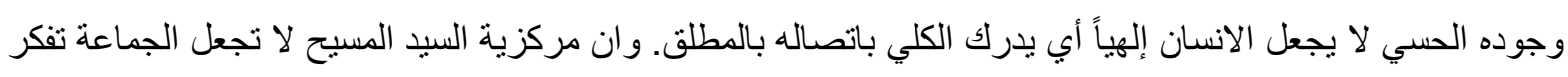

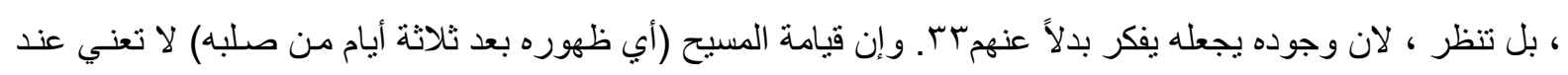

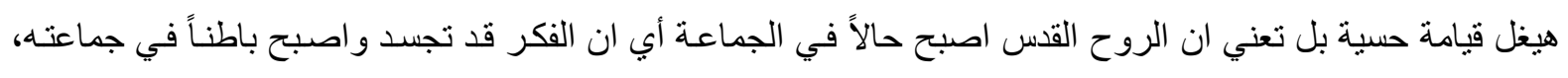

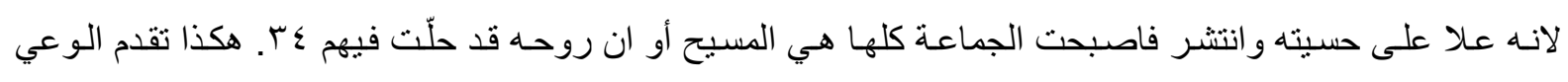
و اصبح كلياً عبر المر احل الثناثة التي مرت بها حياة يسوع ومرّ بها الوعي الإنساني . 


\section{موقف هيغل من فكرة المسيح المخلص (هاسيا)}

بعد العرض الذي قدمناه حول الفكر الهيغيلي ، وموقف هيغل من المطلق، والدين، و المسيحية يصبح من الحتمي

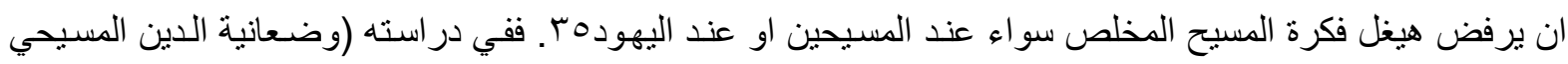
يرفض فكرة المسيح المنتظر ، ويعلل ظهور هذه الفكرة الى تسلل بعض العناصر اليهودية الى المسيحية و يرى هيغل ان

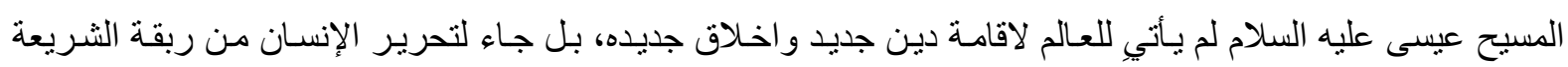

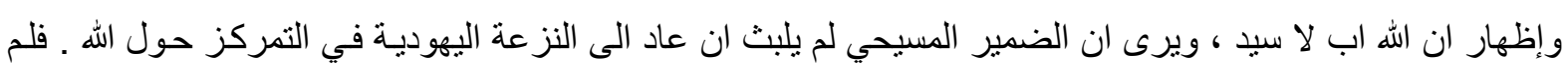

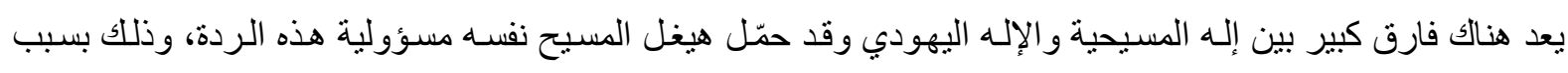

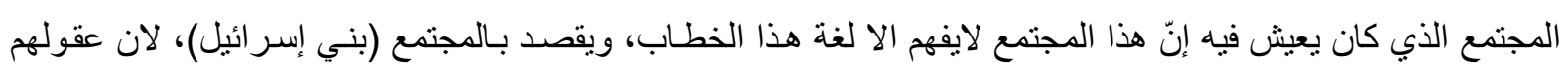

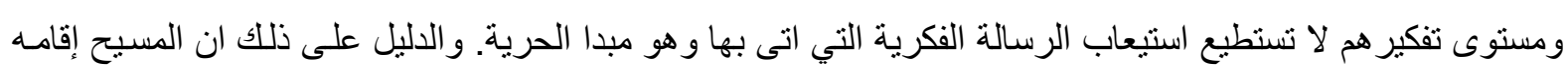

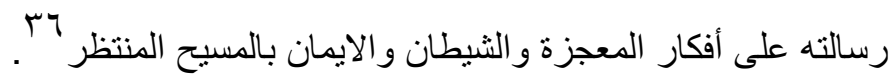

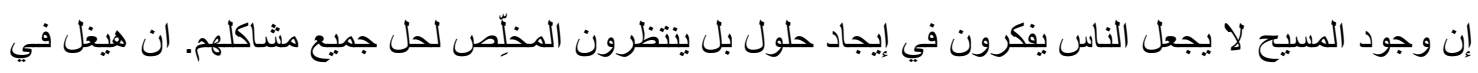

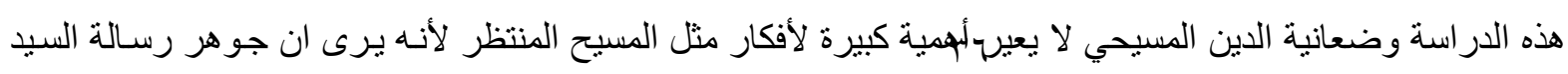

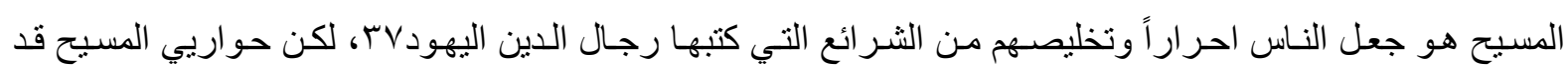

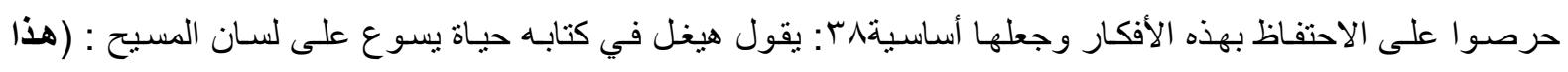
الانتظار الى الماسيّا يوقع أبناء امتي باخطار جسيمة وباربطة مـع احكامهم المسبقة الأخرى وتعصبهم الاعمى فانسه

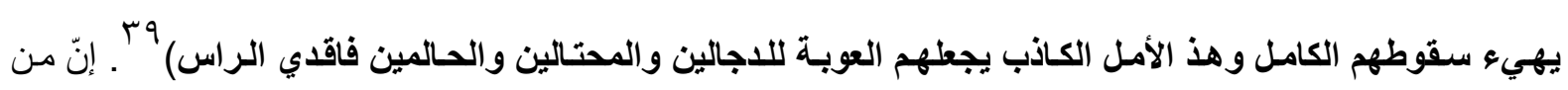

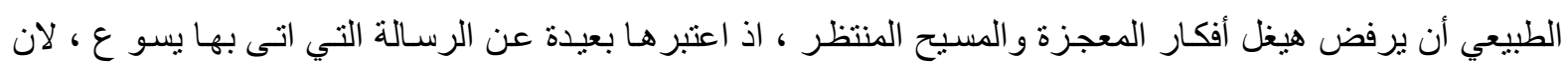

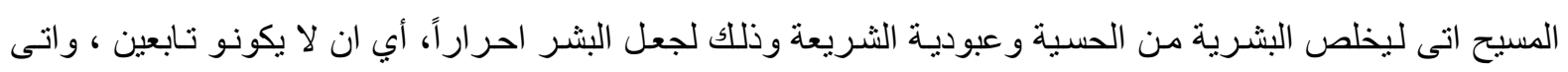

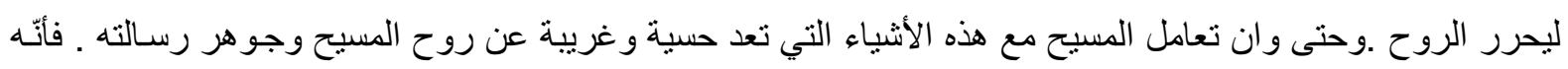

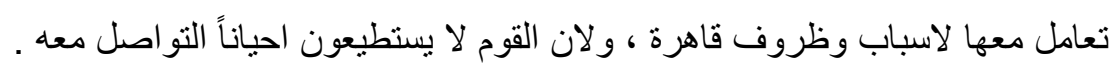

ويتضح موقف هيغل في رفضة لفكرة المسيح المنتظر في نص لـه في كتاب حياة يسوع اذ يستعير هيخل كلام

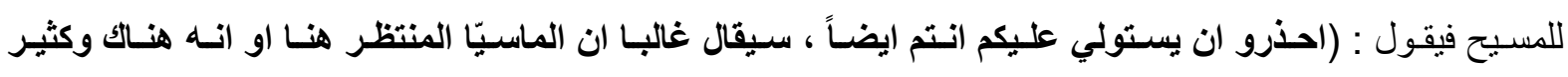

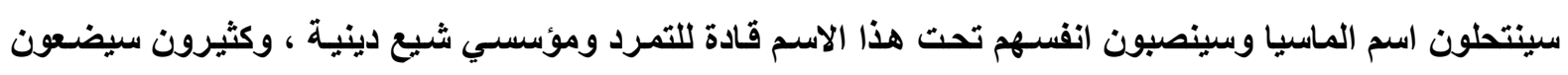
نبوعات ومعجزات حتى يخدعو بقر إمكانهم الصالحين انفسهم) “. يتضح من هذا النص أنّ هيخل يرفض فكرةالمسيح المنتظر، غير أنّ هذه العقيدة يستغلها الكثير من الكذابين المدعين أنهم الماسيا في إنثارة الى (المسيح). و هؤلاء المسحاء الكذابون سوف يعملون الفتن و التمردات ويحدثون الضـرر في المجتمع ويؤسسون فرقاً و

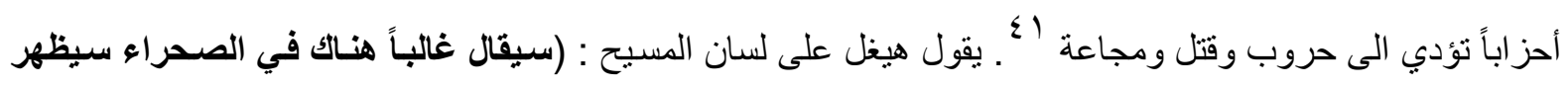

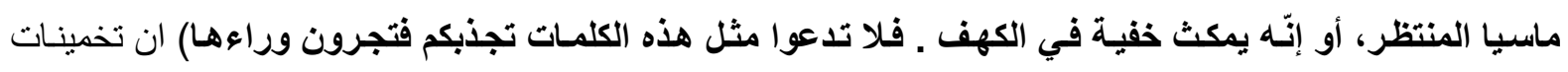

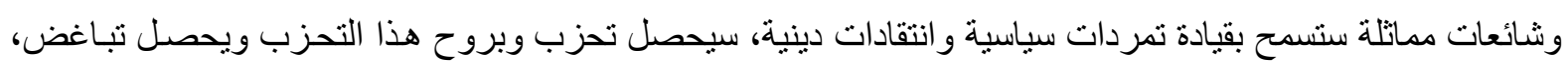

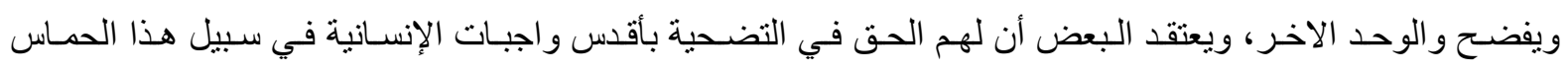

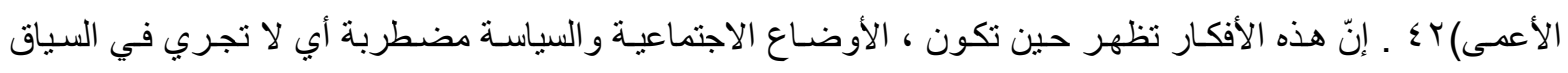


الصحيح ، ويعز على الناس إيجاد الحلول لمشاكلهم فيتتاب الناس حماسً بل هوس، إذ نتمكن منهم هذه الثائعات فيكونون

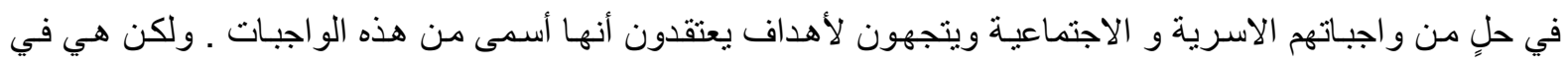
حقيقتها واجبات جوفاء ـ ونتيجة لكل هذا يكون ((خراب الدولة، وانحلال الروابط الاجتماعية و الإنسـانية وتكون هنـاك مجاعة مما يوقع هذه البلدان الثقية فريسة للاعداء الخارجيين فويل للحوامل و الرضع)) "َّ. يبدو أنّ هيغل يأخذ العبرة من تاريخ اليهود الذين ينتظرون مخلصهم فكان ماكان من انحلال الدولة وانفكالك

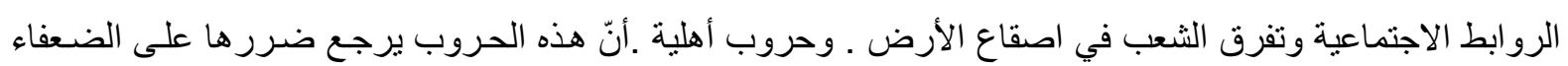

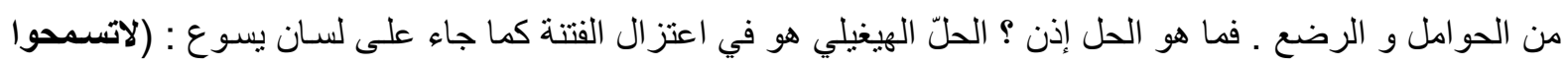

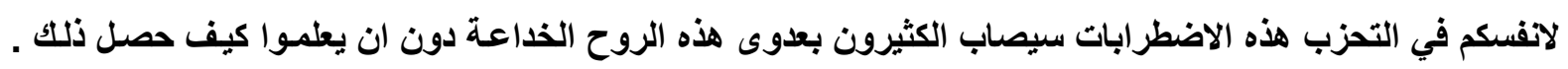
وكثيرون سيستولي عليهم هذا الاعصـار فيبتعدون في كل خطوة عن روح الاعتدال ـ ويرون انفسـهم في النهايـة متورطين في الجرائم وفي الخراب دون ان يكون بأمكانهم التراجع) ؛ ويستمر هيغل في إعطاء الحلول لتلك الفترة

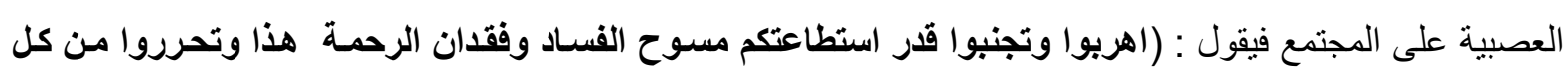
علاقـات القربـى ..... ومهمـا حصل ابقوا مخلصين لمبـادئكم عندما يهاجمكم روح التحزبويـؤلمكم ، بثـرو بالاعتدال وإنصحو بالمحبة والسلام ولاتهتموا بايِي من هذه الأحزاب الاينية او السياسية)) هـ

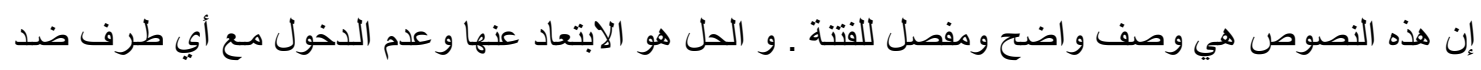

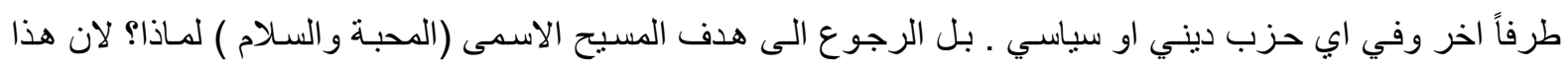

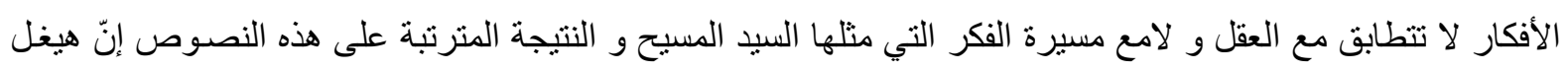

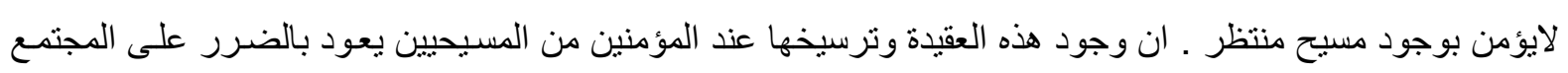

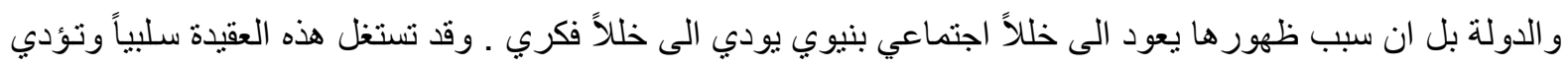

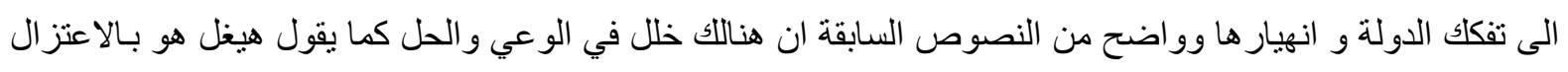
و عدم التحزب لاي مذهب او حزب سياسي او ديني يخوض غمار هذه العقائد لان هذا التعصب ليس فيه كثير فائدة سواء

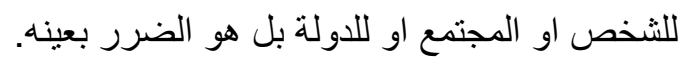

\section{الغلاص وفق الروضية الهيغيلية.}

إن الخلاص بحسب هيغل هو ليس بانتظار (الماسيّا) ، لأن انتظار الماسيا يوقعنا في أخطار نحن في غنى عنها .

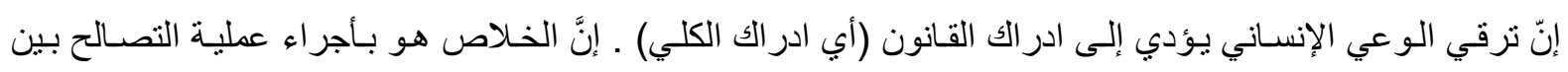

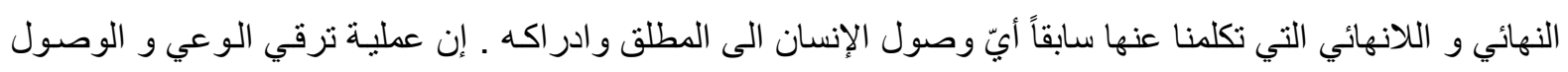

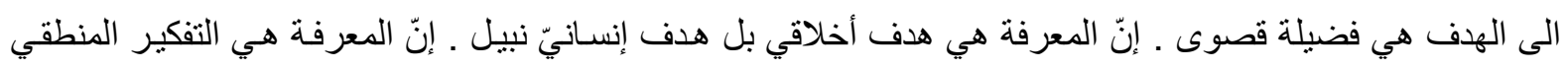

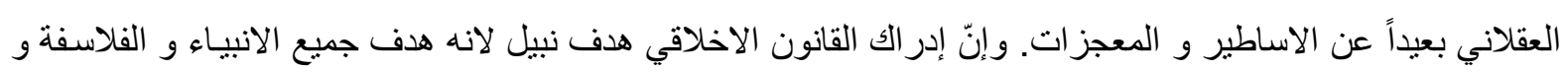

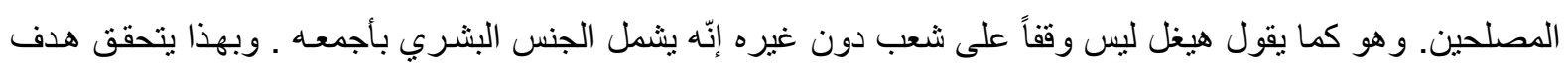

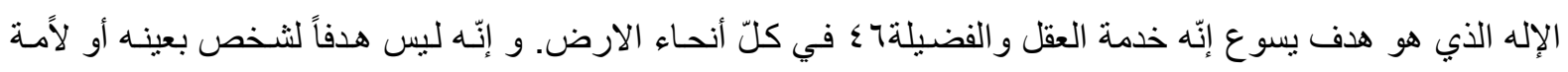

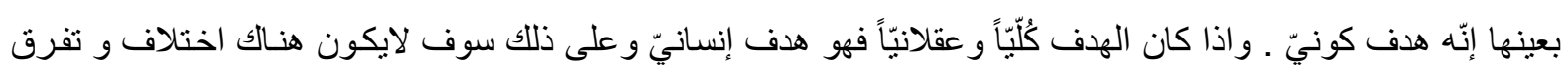

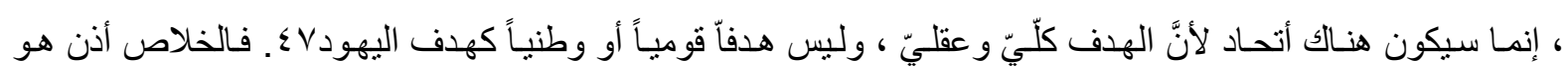

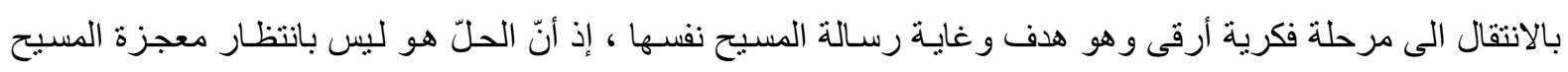


المنتظر ، بل الحلّ هو الاندماج (بالروح القدس) و الكنبسة ـ إذ بالانتقال الى هذه المرحلة أصبحت الجماعة جماعة فكريـة

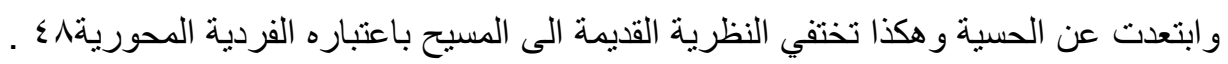

لقد أصبح المسيح بموتـه هو الإلهـ الإنسـاني او الانسـان الإلهي و أصبح الأن لبس (بذاتـه أو لذاته) بـل (لذاته

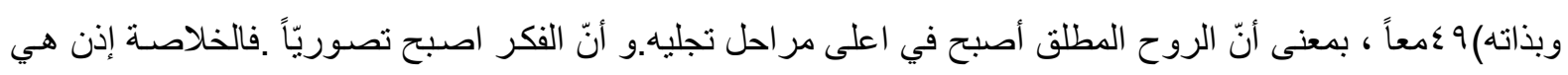

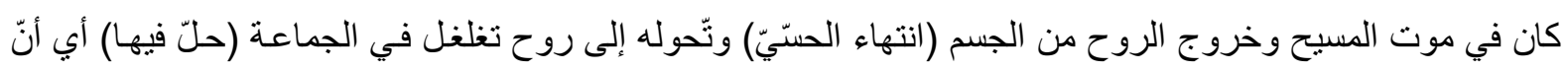

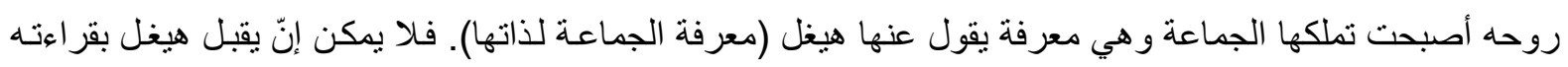

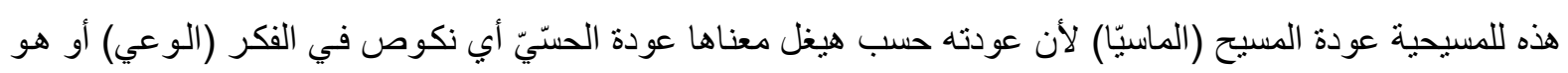

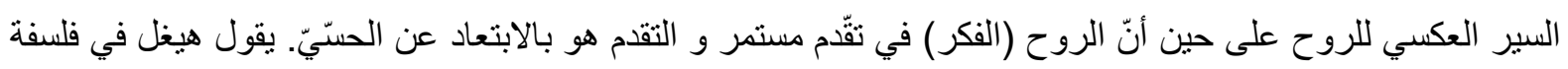

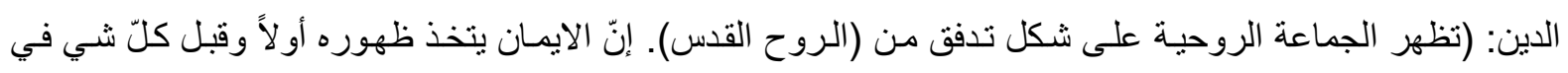

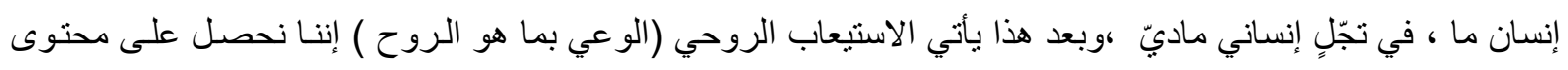

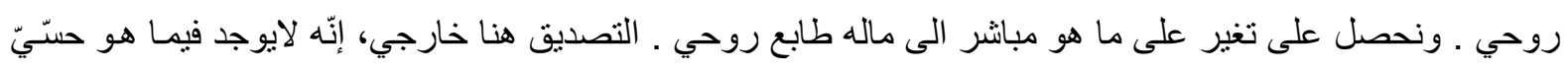

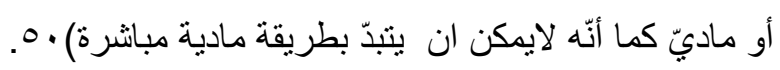

إنّ الخلاص هو في نضوج هذه الجماعة التي ظهرت بفعل نشاط الروح القس التي هي روح المسيح أو روح الله

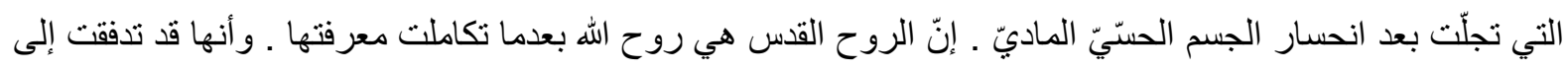

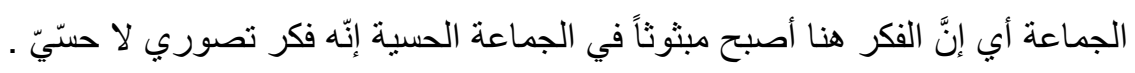
فالخلاص إذن يأني بعد نضوج الديانة المسيحية لأنها ديانة أدركت المطلق و أدركت الهدف الاسمى الذي يسعى

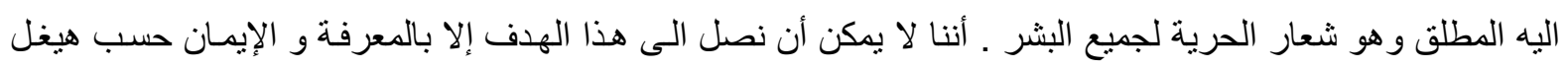

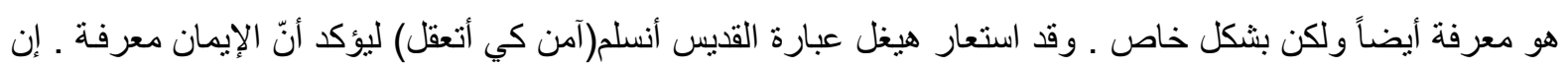

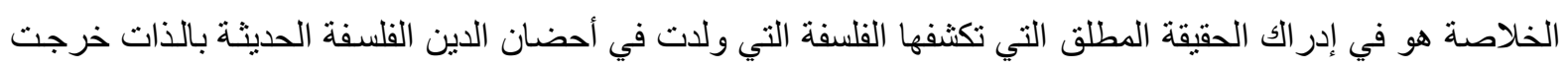
من رحم البروتستانتية التي كان هيغل جزءاً منها. يقول هيغل (الفلسفة الحديثة وحدها هي التي وصلت إلى الفكر العميق الوارد هكذا في (الفحوى) وليس ممكناً على الاطلاق مناقشّة هذه الحقيقة بابتذالات غير فلسفية توحي بفكرة

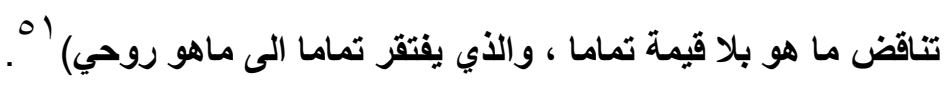
إنَّ الخلاص يأتي امتلاك الحقيقة، وامتلاك الحقيقة ياتي عن طريق معرفتها بكثفها ـ ولكثفها نحتاج الى أدوات

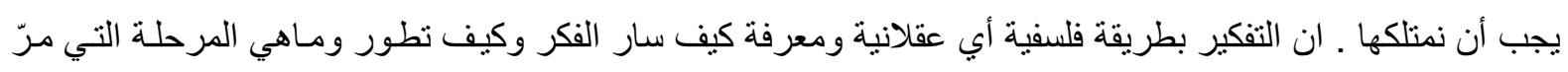

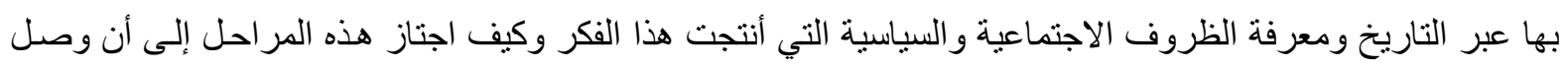
إلى إتمام نضوجه ـ إنّ العقل هو الذي يحرك التاريخ الإنساني ـ وتـاريخ الانسانية هو نتاريخ نطور العقل ـ أمـا الإيمـان

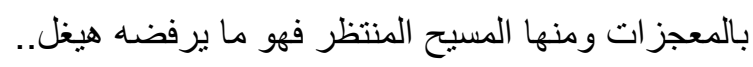

إنّ الإيمان بفكره المسيح المخلص لا تساعد الإنسـان على إدراك المطلق بل تبقيه في المباشرية أو الحسّيّة ـ إنّ

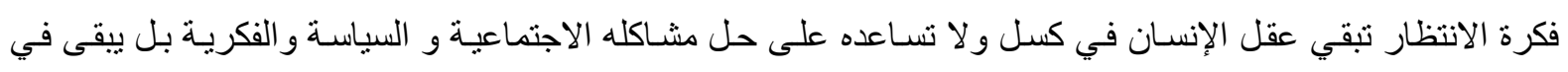
انتظار من يخلصه. فالخلاص إذن يأتي بالفلسفة وحثّ الناس على التفكير بطريقة فلسفية أي عقلية ـ إنّ الفلسفة هي نشاط الأل

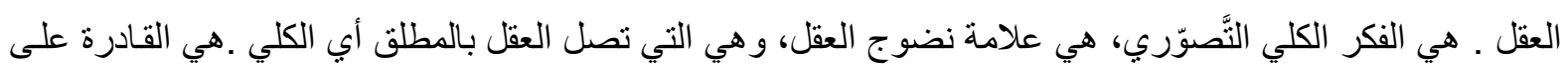


الاتصال باللانهائي ، لان العقل قادرة على إدراك القانون الكلّيّ وهو الذي يجعل الانسـان يشعر بأنه حرّ ، والحريـة هي

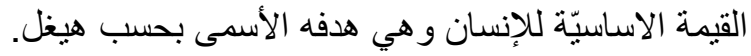

المهامش والتعمليقات

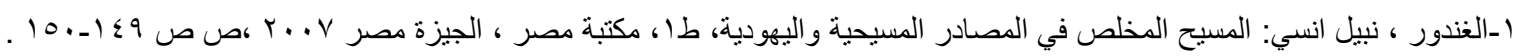

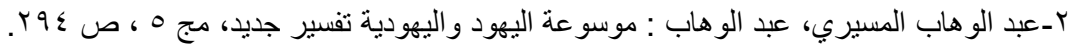

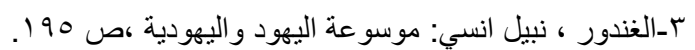

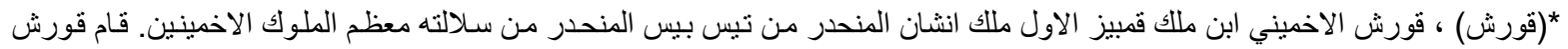

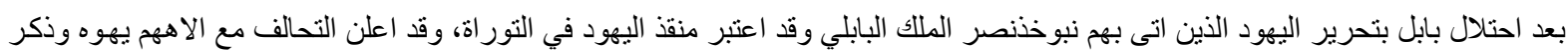

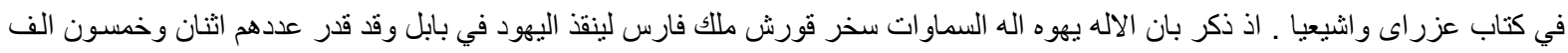

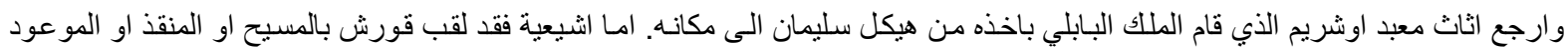
لليهود ـ للمزيد راجع العوادي، مرتضـى جاسب، العوادي قورش الاخميني سبراته ومنجز اته رسالة ماجستير غير منشورة من ،كلية التربية

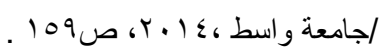
ع-المصدر نفسه: ص ص 109.

0ـالمصدر نفسه : نفس الصفحة.

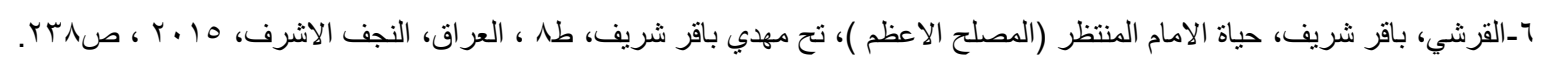

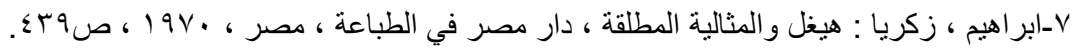

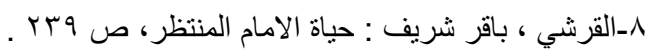

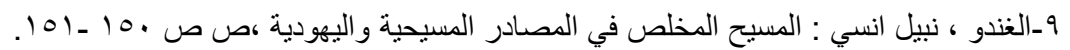

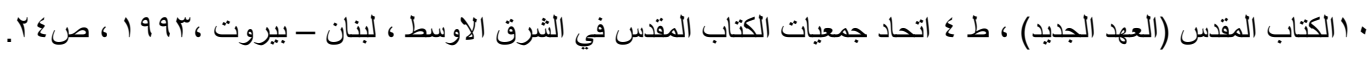

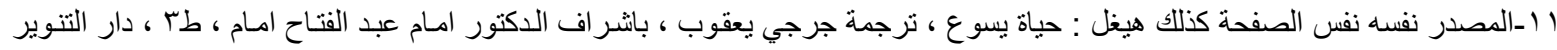

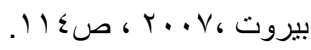

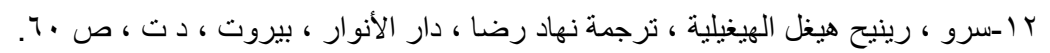

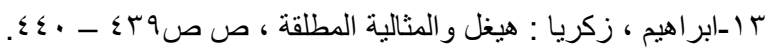
ะ

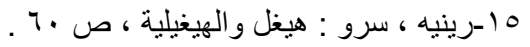

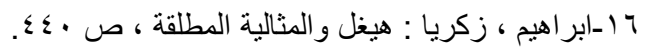

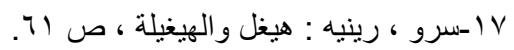

18-Bour GOis .Bernard - L'Ideatism allemande.Atematives et, progress ,paris, editions vrin , 2000,p.26. 19-LEVINAS EMMONUEL,De Diev qaivient at Idee Paris editions vrin,1992,p.79.

كذلك د.عباس حمزة : الاسكاتولوجيا (المصائرية)ومعنى التاريخ في الهيغيلية والفكر الفرنسي ، مجلة الجديد - طر ابلس - ليبيا العدد؟ ،ص

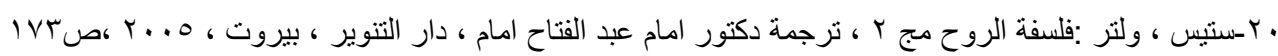

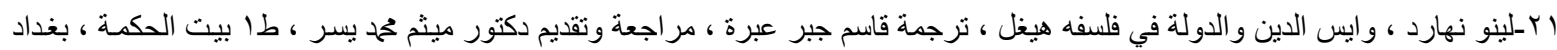

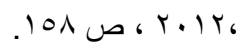

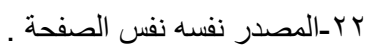
23-NANCY.j-L:Hegel,Liquietude.dungative,paris, edition,Hechette,1997-p.14.

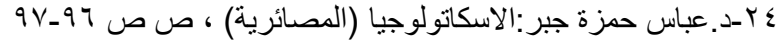

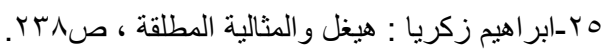


ج ب-هيغل : محاضر ات في فلسفة الدين (الحلقة السادسـة) الله و الفكرة الخالدة ، ترجمة مجاهد عبد المنعم مجاهد ، مطبعة مكتبـة ، دار الحكمـة

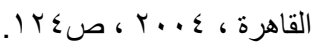

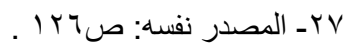

$$
\begin{aligned}
& \text { אץ- المصدر نفسه: ص } \\
& \text { و Үـ المصدر نفسه: نفس الصفحة . }
\end{aligned}
$$

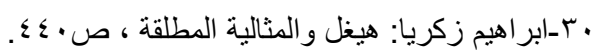

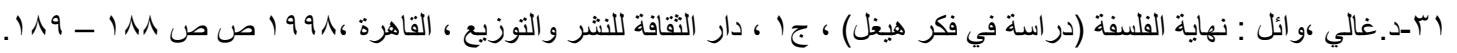

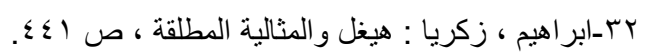

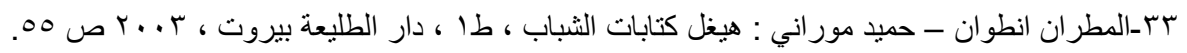

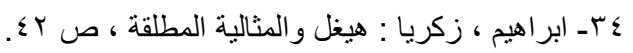

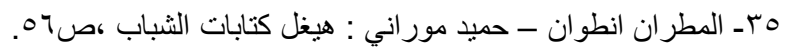

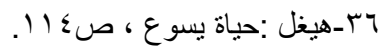
N Vr V المصدر نفسه : نفس الصفحة. مب المصدر نفسه نفس الصفحة.

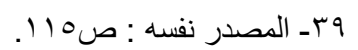

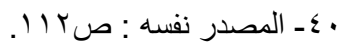

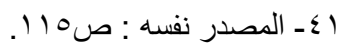
بـ r ؟ ــ المصدر نفسه : نفس الصفحة.

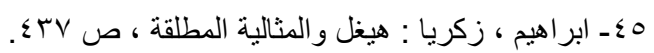

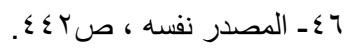

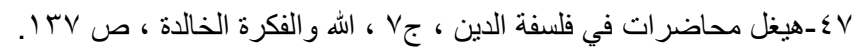

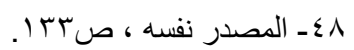

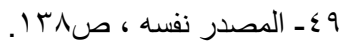

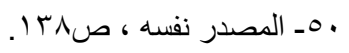

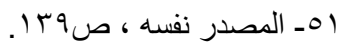

